\title{
Cell-specific Delivery of a Transforming Growth Factor-beta Type I Receptor Kinase Inhibitor to Proximal Tubular Cells for the Treatment of Renal Fibrosis
}

\author{
Jai Prakash, ${ }^{1,5}$ Martin H. de Borst, ${ }^{2}$ Annemiek M. van Loenen-Weemaes, ${ }^{1}$ Marie Lacombe, ${ }^{3}$ Frank Opdam, ${ }^{3}$ \\ Harry van Goor, ${ }^{2}$ Dirk K. F. Meijer, ${ }^{1}$ Frits Moolenaar, ${ }^{1}$ Klaas Poelstra, ${ }^{1}$ and Robbert J. Kok ${ }^{1,4}$
}

Received September 29, 2007; accepted December 3, 2007; published online January 9, 2008

\begin{abstract}
Purpose. Activation of tubular epithelial cells by transforming growth factor-beta (TGF- $\beta$ ) plays an important role in the pathogenesis of renal tubulointerstitial fibrosis. We developed a renally accumulating conjugate of a TGF- $\beta$ type-I receptor kinase inhibitor (TKI) and evaluated its efficacy in vitro and in vivo.

Methods. TKI was conjugated to the protein Lysozyme (LZM) via a platinum-based linker. TKI-LZM was evaluated in human tubular cells (HK-2) for its anti-fibrotic activity. Plasma, kidney and urine drug levels after a single intravenous dose of TKI-LZM in rats were determined by HPLC or immunodetection. Anti-fibrotic effects of TKI-LZM were examined in the unilateral ureteral obstruction (UUO) model.

Results. TKI-LZM conjugate was successfully synthesized at an 1:1 drug/carrier ratio, and inhibited TGF$\beta 1$-induced procollagen-1 $\alpha 1$ gene expression in HK- 2 cells. In vivo, TKI-LZM accumulated rapidly in tubular cells and provided a local depot for 3 days. Interestingly, a single dose of TKI-LZM inhibited the activation of tubular cells and fibroblasts in UUO rats and reduced renal inflammation. In contrast, free TKI at an equimolar (low) dosage exhibited little effects.

Conclusions. Inhibition of TGF-beta signaling by local drug delivery is a promising antifibrotic strategy, and demonstrated the important role of tubular activation in renal fibrosis.
\end{abstract}

KEY WORDS: lysozyme; proximal tubular cells; transforming growth factor; tyrosine kinase inhibitor; unilateral ureteral obstruction.

\section{INTRODUCTION}

Transforming growth factor-beta (TGF- $\beta$ ), a multifunctional cytokine, plays a crucial role in the pathogenesis of many renal diseases which lead to renal fibrosis (1). During renal injury, the active form of TGF- $\beta$ is either locally produced by resident or by infiltrated cells, or systemically derived. Irrespective of its source, TGF- $\beta$ can activate tubular epithelial cells causing their transformation into fibroblasts through epithelial-mesenchymal transdifferentiation (2).

\footnotetext{
${ }^{1}$ Department of Pharmacokinetics and Drug Delivery, Groningen Research Institute for Pharmacy, University of Groningen, Antonius Deusinglaan 1, 9713 AV, Groningen, The Netherlands.

${ }^{2}$ Department of Pathology and Laboratory Medicine, University Medical Centre of Groningen, Groningen, The Netherlands.

${ }^{3}$ Kreatech Biotechnology B.V., Vlierweg 20, 1032 LG, Amsterdam, The Netherlands.

${ }^{4}$ Department of Pharmaceutics, Utrecht Institute for Pharmaceutical Sciences, Utrecht University, Utrecht, The Netherlands.

${ }^{5}$ To whom correspondence should be addressed. (e-mail: J.Prakash@ rug.nl)

ABBREVIATIONS: ESI-MS, electronspray ionization mass spectrometry; FCS, fetal calf serum; HPLC, high performance liquid chromatography; LZM, Lysozyme; MCP-1, monocyte chemoattractant protein-1; PBS, phosphate buffered saline; TKI, TGF-beta receptor type-I kinase inhibitor; ULS, Universal Linkage System.
}

Eventually, resident and epithelial cell derived fibroblasts are transformed into myofibroblasts and produce extracellular matrix (ECM) proteins (3). TGF- $\beta$ binds to its type-II receptor, which subsequently associates with the type-I receptor known as Activin Receptor Like Kinase 5 (ALK5) (4). ALK5 activates downstream signaling cascades and thereby participates in the development of renal fibrosis by regulating ECM deposition (5). Blockade of ALK5 in renal tubular cells therefore seems an attractive therapeutic strategy to prevent or attenuate tubulointerstitial fibrosis.

Recently, ALK5 inhibitors have been developed and evaluated for the inhibition of TGF- $\beta$ action in various in vitro systems (6). These inhibitors bind to the ATP-binding pocket of the kinase domain of the TGF- $\beta$ type I receptor and inhibit the subsequent activation of downstream pathways $(6,7)$. Recent studies have demonstrated beneficial effects of ALK5 inhibitors on lung, kidney and liver fibrosis in animal models (8-11). However, relatively high and multiple doses had to be administered to achieve therapeutic effects. Moreover, systemic administration of an ALK5 inhibitor may elicit immunological side-effects at high doses, since TGF- $\beta$ plays an essential role in immune tolerance via the regulation of lymphocyte proliferation and differentiation (12).

We have developed a renal drug delivery system $(13,14)$ which is also applicable to the presently studied class of kinase inhibitors. Using a new linking technology, Universal 
Linkage System (ULS ${ }^{\mathrm{TM}}$ ), drug molecules are coupled to the renal carrier protein lysozyme (LZM), providing drug-LZM conjugates that accumulate efficiently in the kidneys (15). In the present study, we applied this technology to a TGF- $\beta$ receptor kinase inhibitor (3-(pyridin-2-yl)-4-(4-quinonyl)]1H-pyrazole; TKI) which inhibits ALK5 and several other kinases including p38 MAPkinase (6). We selected this compound because it contained the required functional group (aromatic nitrogen) to couple with LZM using ULS. We first examined the capability of TKI to inhibit inflammatory and fibrotic events in cultured renal tubular cells. Next, we conjugated TKI to LZM, characterized the obtained TKILZM conjugate in vitro in renal tubular cells and studied its pharmacokinetics in healthy rats. We furthermore studied the cellular and renal handling of this type of products using a rhodamine-ULS-LZM conjugate. Finally, we evaluated the therapeutic potential of TKI-LZM in the unilateral ureteral obstruction (UUO) model for renal fibrosis.

\section{MATERIALS AND METHODS}

The ALK5 inhibitor (3-(pyridin-2-yl)-4-(4-quinonyl)]-1Hpyrazole; TKI) was purchased from Calbiochem (Darmstadt, Germany). Human recombinant TGF- $\beta 1$ was purchased from Roche Diagnostics, Mannheim, Germany. Rhodamine-ULS was purchased from Kreatech Biotechnology, Amsterdam, The Netherlands.

\section{Synthesis of TKI-ULS-lysozyme and Rhodamine-ULS-lysozyme}

TKI was conjugated to LZM using ULS via platinum coordinative linkages. Since drug-ULS adducts react readily with methionine residues, the renal carrier LZM was enriched with surface-exposed methionine groups as described before (15). A freshly prepared solution of ULS-mononitrate-monochloride (20.5 mM, dissolved in DMF) was added in an equimolar amount to TKI $(9.98 \mathrm{mg}, 36.6 \mu \mathrm{mol})$ and reacted at $37^{\circ} \mathrm{C}$ overnight. TKI-ULS product was characterized by HPLC, Pt-NMR and LC-MS analyses.

TKI-LZM was synthesized by reacting TKI-ULS $(2.1 \mu \mathrm{mol}$, $7 \mathrm{mg} / \mathrm{ml})$ to methionine-LZM $(0.7 \mu \mathrm{mol}, 10 \mathrm{mg} / \mathrm{ml}$ in $0.02 \mathrm{M}$ tricine/sodium nitrate buffer, $\mathrm{pH} 8.5)$. Electron Spray Ionization-Mass Spectrometry (ESI-MS) analysis confirmed the formation of TKI-LZM conjugate. The amount of conjugated drug was quantified after displacing TKI using sodium dithiocarbamate (Merck, Darmstadt, Germany). TKI-LZM was also characterized for its stability and drug-release properties. TKILZM $(100 \mu \mathrm{g} / \mathrm{ml})$ was incubated in PBS, $5 \mathrm{mM}$ glutathione in $\mathrm{PBS}$, or serum at $37^{\circ} \mathrm{C}$ for $24 \mathrm{~h}$. Then, samples were immediately processed for HPLC analysis as described below.

To synthesize Rhodamine-ULS-LZM, Rhodamine-ULS $(2.1 \mu \mathrm{mol}$, in DMF $)$ was reacted to methionine-LZM $(0.7 \mu \mathrm{mol})$ and purified according to the same protocol as described for TKI-LZM. The eventually provided red-colored conjugate was characterized by ESI-MS.

\section{HPLC Analysis of TKI}

TKI was analysed by reverse-phase HPLC on a Waters system (Waters, Milford, MA, USA). Separations were achieved with a $\mathrm{C}_{18}$ reversed-phase SunFire ${ }^{\mathrm{TM}}$ column $(150 \times 4.6 \mathrm{~mm}$ i.d., $5-\mu \mathrm{m}$ particle size, Waters $)$ preceded by guardPak precolumn (Waters). TKI was monitored at $320 \mathrm{~nm}$ after eluting with the mobile phase (water-acetonitriletrifluoroacetic acid, 91:09:0.1, $v / v / v ; \mathrm{pH} 2.0)$ at flow rate $1 \mathrm{ml} / \mathrm{min}$ TKI eluted at the retention time of $5.8 \mathrm{~min}$. The peak heights were measured to quantify the drug concentrations. To determine TKI in serum and urine samples, $100 \mu \mathrm{l}$ of the sample was extracted with $3 \mathrm{ml}$ of diethylether twice. After evaporating the organic layer, the residue was reconstituted in $100 \mu \mathrm{l}$ of mobile phase and $25 \mu \mathrm{l}$ of it was injected into HPLC. To estimate TKI in tissue homogenates, $100 \mu \mathrm{l}$ of the sample was treated with $200 \mu \mathrm{l}$ of methanol, vortex and centrifuged to precipitate proteins. About $50 \mu \mathrm{l}$ of the clear supernatant was injected into HPLC. The lower limit of detection (LLOD) and the lower limit of quantitation (LLOQ) of TKI were 100 and $250 \mathrm{ng} / \mathrm{ml}$, respectively in serum, urine and tissue homogenates.

\section{Cell Experiments}

\section{Effects of TKI and TKI-LZM in Renal Tubular Cells}

NRK-52E (normal rat kidney) tubular epithelial cells were kindly provided by Prof. Russel, University of Nijmegen, The Netherlands. Cells were cultured in Dulbecco's modified Eagle's medium (DMEM; BioWhittaker, Verviers, Belgium) supplemented with 5\% fetal calf serum (FCS, BioWhittaker), $4 \mathrm{mM} \mathrm{L}$-glutamine, penicillin $(50 \mathrm{U} / \mathrm{ml})$ and streptomycin (50 ng/ml) at $37^{\circ} \mathrm{C} / 5 \% \mathrm{CO}_{2}$ in air. Human kidney tubular cells (HK-2) were obtained from ATCC (Manassas, VA) and grown in Roswell Park Memorial Institute (RPMI)-1640 medium supplemented with $10 \%$ FCS, 2 mM L-glutamine, penicillin $(100 \mathrm{U} / \mathrm{ml})$ and streptomycin $(100 \mathrm{ng} / \mathrm{ml})$ at $37^{\circ} \mathrm{C}$ in $5 \% \mathrm{CO}_{2} /$ air. To examine the effects of TKI and TKILZM, NRK-52E or HK-2 cells were treated with different compounds. NRK-52E or HK-2 cells $\left(6 \times 10^{4}\right)$ were seeded in 12 -well plates and grown for $24 \mathrm{~h}$ to achieve $80 \%$ confluency and then deprived from serum for $24 \mathrm{~h}$. Thereafter, the cells were preincubated for $2 \mathrm{~h}$ with TKI $(10 \mu \mathrm{M})$ and then incubated with either BSA $(30 \mathrm{mg} / \mathrm{ml})$ or TGF- $\beta 1(10 \mathrm{ng} / \mathrm{ml})$ for $24 \mathrm{~h}$ in serum free medium. To observe the effects in HK2 cells, TKI-LZM ( 8 or $80 \mu \mathrm{g} / \mathrm{ml}$ are equivalent to 1 or $10 \mu \mathrm{M}$ TKI, respectively) or methionine-modified LZM (LZM, 8 or $80 \mu \mathrm{g} / \mathrm{ml}$ ) was added at the time of serum deprivation whereas TKI $(1$ or $10 \mu \mathrm{M})$ was added $1 \mathrm{~h}$ before adding TGF- $\beta 1$ to the cells. Control cells were treated with the serum-free medium similar to the other treatments without adding any activator or drug. After $24 \mathrm{~h}$ of incubation with activators, cells were processed to isolate total RNA and, then mRNA were determined by quantitative real-time RT-PCR as described below.

\section{Uptake Study of Rhodamine-ULS-LZM in NRK-52E and HK-2 Cells}

Since some cultured renal tubular cell lines may lose the receptors involved in the uptake of proteins from the urinary lumen, we compared the protein uptake property of NRK$52 \mathrm{E}$ and HK-2 cells. Cells $\left(3 \times 10^{4}\right)$ were seeded in 24 -well plate and grown until they achieved $70-80 \%$ confluency. 
Then, cells were incubated with Rhodamine-ULS-LZM $\left(100 \mu \mathrm{g} / \mathrm{ml}\right.$ per well) for $2 \mathrm{~h}$ at $37^{\circ} \mathrm{C}$. To compete for receptor-mediated endocytosis, cells were preincubated for 15 min with 100-fold excess of LZM. Cells were washed with cold PBS three times, dried and examined under the fluorescent microscope to observe uptake of the conjugate.

\section{Animal Experiments}

Normal male Wistar rats (220-240 g) were obtained from Harlan (Zeist, The Netherlands). Animals were kept in cages and maintained with ad libitum diet (Harlan), at $12 \mathrm{~h}$ light and $12 \mathrm{~h}$ dark cycle. All experimental protocols for animal studies were approved by the Animal Ethics Committee of the University of Groningen.

\section{Pharmacokinetic Studies with TKI-ULS-LZM and Rhodamine-ULS-LZM}

An intravenous dose of the TKI-LZM conjugate $(20 \mathrm{mg} / \mathrm{kg}$ equivalent to $515 \mu \mathrm{g} / \mathrm{kg}$ TKI dissolved in $5 \%$ glucose) was administered to rats $(n=12)$. At indicated time points, animals were sacrificed under general anesthesia (2\% isoflurane in 2:1 $\mathrm{O}_{2} / \mathrm{N}_{2} \mathrm{O}, 11 \mathrm{~min}^{-1}$ ) and blood samples were collected by heart puncture and organs were isolated after gently flushing with saline through abdominal aorta. Urine samples were collected using metabolic cages. Kidneys were weighed, homogenized $(1: 3 w / v$, PBS $)$ and then stored at $-80^{\circ} \mathrm{C}$. Part of the organs was processed for immunohistochemical analysis. To measure drug levels, samples were treated with $0.5 \mathrm{M}$ potassium thiocyanate (serum, kidney homogenates) or $0.1 \mathrm{M}$ sodium dithiocarbamate (urine) at $80^{\circ} \mathrm{C}$ for $24 \mathrm{~h}$ to release TKI from linker and then measured by HPLC as explained above. TKI amount was calculated from standard curves which were made by incubating TKI-LZM in tissue homogenates or serum after treating similar to the samples. Localization of TKI-LZM in the kidneys was detected by indirect anti-LZM immunostaining method on cryostat sections. Sections were incubated with primary rabbit anti-LZM polyclonal antibody (Chemicon, CA) for $1 \mathrm{~h}$ and then endogenous peroxidase activity was removed with 3\% hydrogen peroxide. Then, sections were incubated with secondary goat anti-rabbit antibody (Dako, Denmark) labeled with horseradish peroxidase. The peroxidase activity was visualized as red color using 3-amino-9-ethyl-carbazole and, the counter staining was performed with Mayer's hematoxylin.

To investigate the cellular handling of drug-ULS-LZM in the kidneys, rats were injected intravenously with Rhodamine-ULS-LZM conjugate $(20 \mathrm{mg} / \mathrm{kg}$ dissolved in $5 \%$ glucose) and sacrificed at 1 or $24 \mathrm{~h}$ after administration. Localization of the conjugate was determined by fluorescence microscopy of acetone-fixed cryosections.

\section{Effect of TKI-LZM in Rats with Unilateral Ureteral Obstruction}

The efficacy of TKI-LZM was studied in the unilateral ureteral obstruction (UUO) model which is characterized by a significant induction of TGF- $\beta$ production during the process of renal fibrosis. Animals were divided into four groups: normal rats $(n=4)$ and UUO animals treated with either vehicle ( $5 \%$ glucose, $n=5)$, TKI-LZM $(25 \mathrm{mg} / \mathrm{kg}$ equivalent to $630 \mu \mathrm{g} / \mathrm{kg}$ TKI, $n=5)$ or free, unconjugated TKI $(630 \mu \mathrm{g} / \mathrm{kg}, n=5)$. TKI was dissolved in $20 \%$ hydroxylpropyl- $\beta$-cyclodextrin in water with $5 \%$ DMSO, whereas TKI-LZM was dissolved in 5\% glucose. We have found that $20 \%$ hydroxylpropyl- $\beta$-cyclodextrin does not affect renal inflammation and fibrosis (data not shown). To allow unhindered uptake of the products in the kidneys, rats were injected intravenously with either of these compounds $2 \mathrm{~h}$ before the ureteral obstruction. Left kidneys and ureter were exposed via a flank-incision under anesthesia (2\% isoflurane in 2:1 $\mathrm{O}_{2} / \mathrm{N}_{2} \mathrm{O}, 11 \mathrm{~min}^{-1}$ ), after which the ureter was ligated at two sites with 4-0 silk near the hilum. After 3 days, animals were sacrificed and kidneys were gently flushed and harvested. Kidney cortex pieces were snap-frozen to isolate RNA. Kidney pieces were fixed in $4 \%$ formalin solution in PBS to make paraffin-embedded sections. Immunohistochemical stainings for the tubular cells dedifferentiation (vimentin), profibrotic marker alpha-smooth muscle actin ( $\alpha$-SMA) and monocytes/macrophages marker (ED-1) were performed on paraffin-embedded sections.

\section{Immunohistochemistry}

Vimentin, alpha-smooth muscle actin ( $\alpha$-SMA) and ED1 immunostainings were performed on $4-\mu \mathrm{m}$ thick paraffinembedded sections. Sections were deparaffinized in xylene and rehydrated in alcohol and distilled water. Heat-induced antigen retrieval was achieved by incubation in microwave for $15 \mathrm{~min} 300 \mathrm{~W}$ with $1 \mathrm{mM}$ EDTA $\mathrm{pH} 8.0$ for vimentin and in $0.1 \mathrm{M}$ Tris/ $\mathrm{HCl}$ buffer ( $\mathrm{pH} 9.0$ ) overnight at $80^{\circ} \mathrm{C}$ for ED-1 and $\alpha$-SMA. Endogenous peroxidase activity was blocked by $0.03 \% \mathrm{H}_{2} \mathrm{O}_{2}$ /sodium azide. Slides were then incubated with primary antibodies against vimentin (DAKO, Glostrup, Denmark), $\alpha$-SMA (clone 1A4, Sigma, MO, USA) or the rat macrophage marker ED-1 (Serotec, Oxford, UK). Binding was detected by subsequent incubation with peroxidaselabelled rabbit anti-mouse and goat anti-rabbit polyclonal antibodies (DAKO, Glostrup, Denmark), respectively, in the presence of $1 \%$ normal rat serum. The peroxidase activity was visualised using 3,3'-diaminobenzidine tetrahydrochloride $(\mathrm{DAB}+, \mathrm{DAKO})$. Sections were counterstained with hematoxyllin for vimentin or with periodic acid Schiff's base (PAS) for $\alpha$-SMA and ED-1 and then mounted with Kaiser's glycerin gelatin. The extent of the staining was detemined manually by scoring different fields of each section in the blinded manner. Stainings were scored as follows: -, no staining; +/-, very weak; +, weak; ++, moderate; +++, strong; ++++ , very strong staining.

\section{Determination of $m R N A$ Expression}

Total RNA was isolated from the cells using Stratagene Microkit (Stratagene, La Jolla, CA). RNA content was measured by a nanodrop UV-detector (NanoDrop Technologies, Wilmington, DE). RNA purity was checked for DNA contamination with A260/A280 nm ratio. No DNA contamination was found as the ratio was $>1.8$. cDNA was synthesized from the similar amount of RNA using the Superscript III first strand synthesis kit (Invitrogen, Carlsbad, CA). Gene expression levels for the following genes were measured by quantitative real-time RT-PCR using an ABI 
<smiles>O=[N+]([O-])[P+]1(Cl)NCCN1</smiles>

TKI
ULS

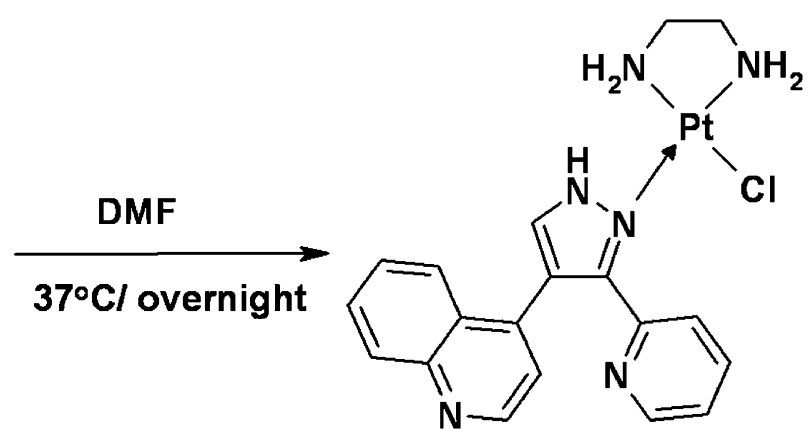

TKI-ULS

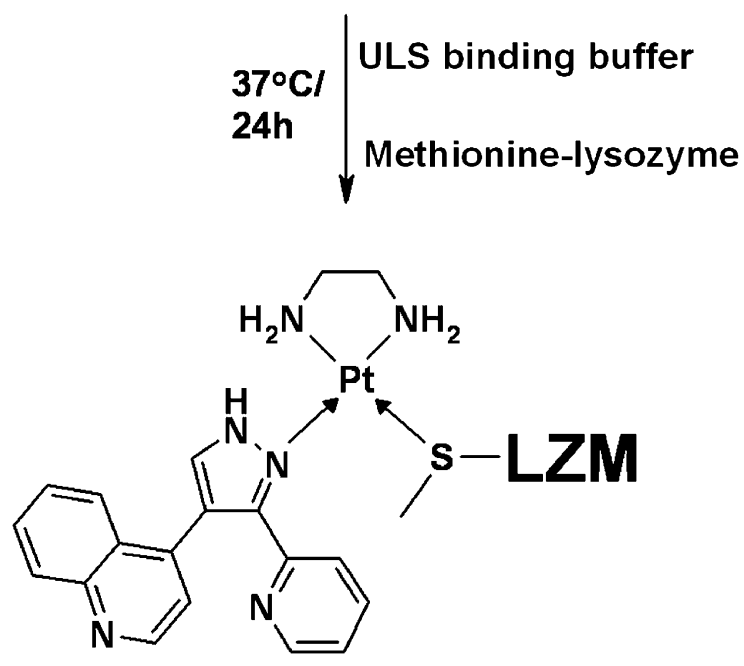

TKI-ULS-lysozyme

Fig. 1. Synthesis scheme of TKI-ULS-lysozyme conjugates. LZM Lysozyme; ULS Universal Linkage System.

Prism 7900HT Sequence Detection System (Applied Biosystems., Foster City, CA). The primers for the rat species were obtained from Sigma-Genosys (Haverhill, UK). The rat primers for Glyceraldehyde-3-phosphate dehydrogenase (GAPDH), monocyte chemoattractant protein-1 (MCP-1), procollagen-1 $\alpha 1$ and tissue inhibitor of metalloproteinase-1 (TIMP-1) have been reported earlier (15) whereas primers for $\alpha$-SMA were 5'-GACACCAGGGAGTGATGGTT-3' and 5'-GTTAGCAAGGTCGGATGCTC-3'. The TaqMan primers for Human species were obtained from Applied Biosystems (Assay-On-Demand).
For NRK-52E cells and rat tissues, SYBR® Green PCR Master Mix (Applied Biosystems, Warrington, UK) and for HK2 cells qPCR $^{\text {TM }}$ Mastermix Plus (Eurogentec, Seraing, Belgium) were used as fluorescent probes for real-time RT-PCR. The cDNA amplification was performed until 40 cycles followed by dissociation cycle. The final product was examined to provide a single peak in the dissociation curve. The cDNA amplification was performed and the threshold cycle number $(\mathrm{Ct})$ was calculated for each gene and then relative gene expressions were calculated using $\Delta \Delta \mathrm{Ct}$ quantitation method after normalization to the expression of reference gene GAPDH.

Table I. Characterization of TKI-LZM Conjugate

\begin{tabular}{|c|c|c|c|c|}
\hline Constructs & Synthesis Ratio & Coupling Ratio & Major Peaks in ESI-MS & $\%$ Yield \\
\hline TKI-ULS & 1:1 (TKI/ULS-NO $\left.{ }_{3}\right)$ & 1:1 (TKI/ULS) & 561 & 77.3 \\
\hline Methionine-LZM & 2.5:1 (Boc-Met-NHS/LZM) & 1.5:1 (met/LZM) & $14538\left(\right.$ met $_{1}$-LZM) 14769 ( met $_{2}$-LZM) & $>98$ \\
\hline TKI-LZM & 3:1 (TKI-ULS/met-LZM) & 1.2:1 (TKI/LZM) & $\begin{array}{l}15063\left(\mathrm{TKI}_{1}-\text { met }_{1}-\mathrm{LZM}\right) \\
15294\left(\mathrm{TKI}_{1}-\text { met }_{2}-\mathrm{LZM}\right) \\
15820\left(\mathrm{TKI}_{2}-\text { met }_{2} \text {-LZM }\right)\end{array}$ & $>99$ \\
\hline
\end{tabular}

TKI concentration was determined using HPLC after releasing it from ULS by incubating with $\mathrm{KSCN}$ at $80^{\circ} \mathrm{C}$ overnight as described in "MATERIALS AND METHODS". TKI to LZM coupling ratio is the average of three different synthesis batches. Methionine/LZM ratio was estimated from the ESI-MS data 
A
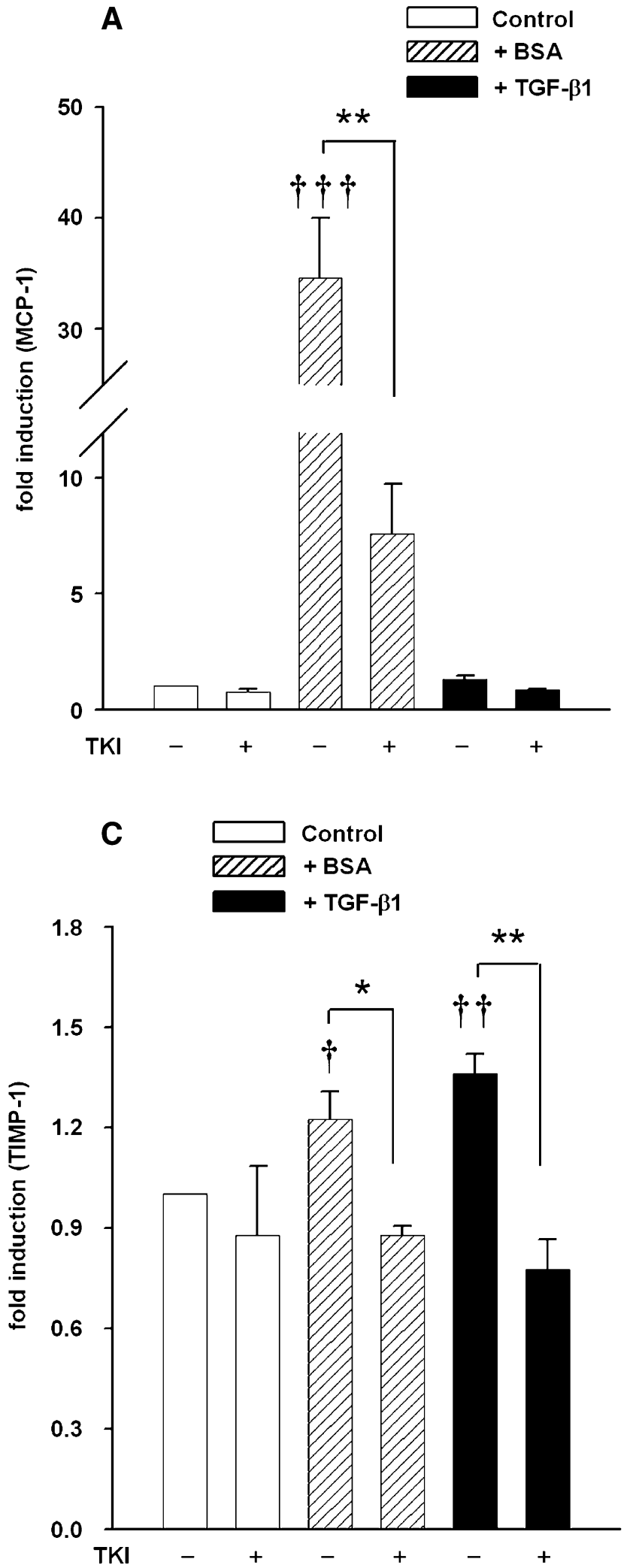

B
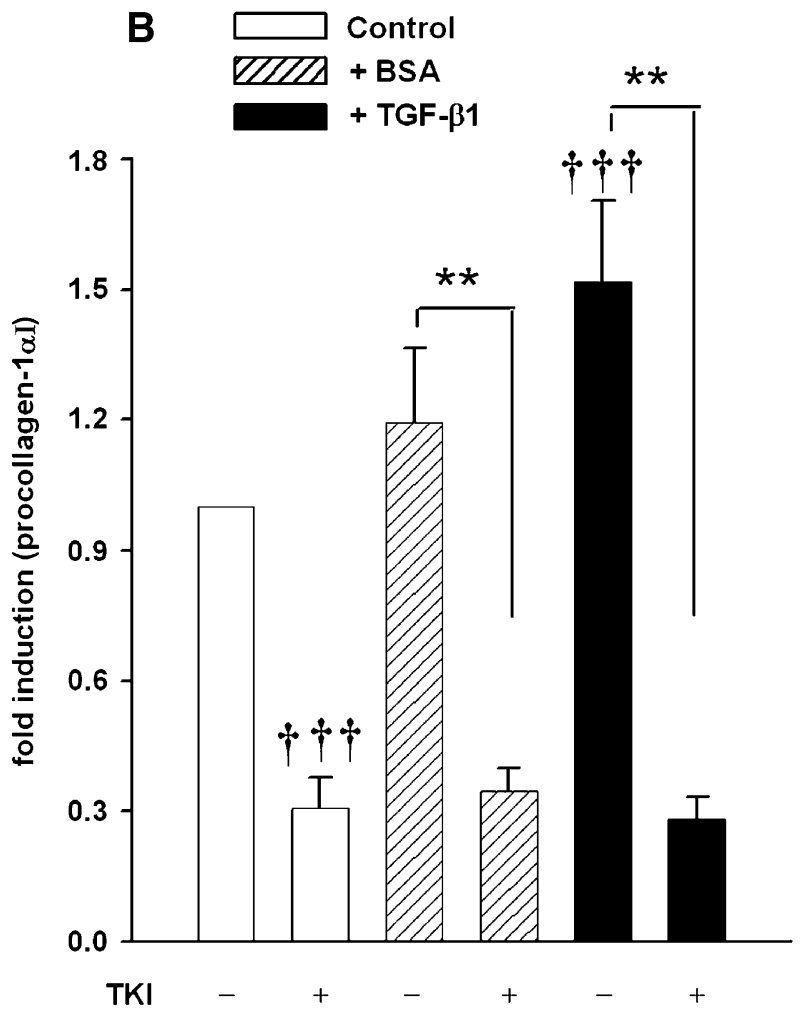

D

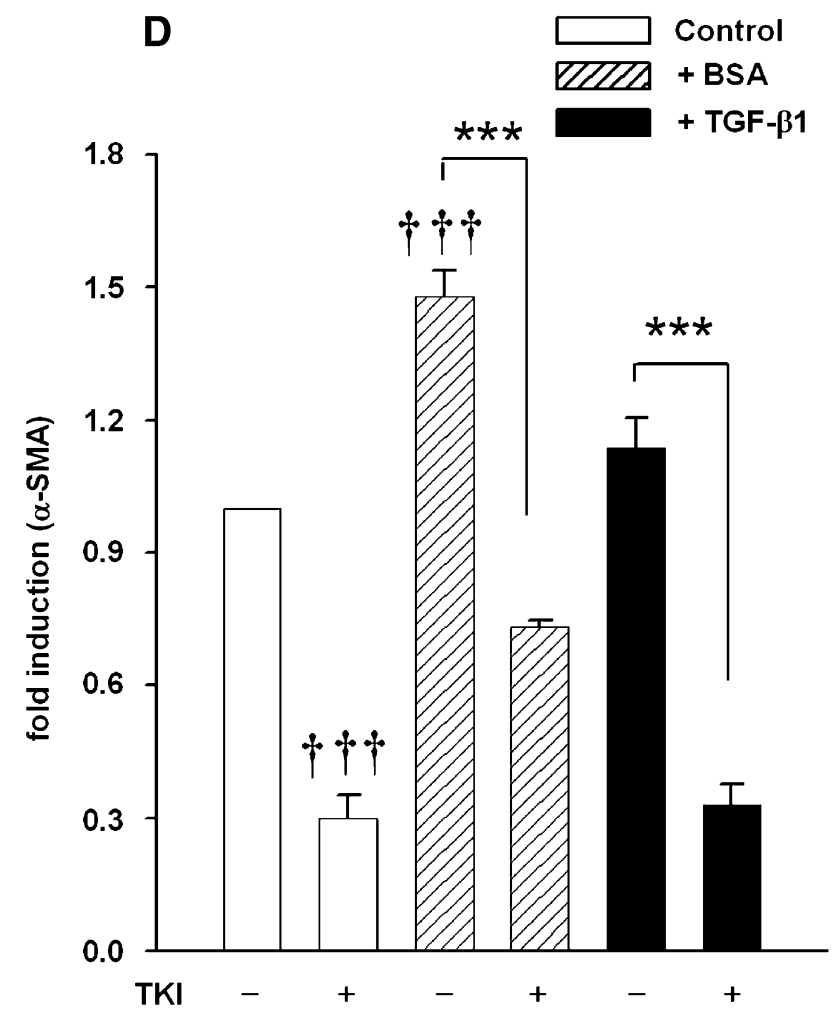

Fig. 2. Effects of TKI on albumin or TGF- $\beta 1$-induced gene expressions of MCP-1 (A), procollagen-1 $\alpha 1$ (B), TIMP-1 (C) and $\alpha$-SMA (D) in NRK-52E renal tubular cells. Cells were grown to $80 \%$ confluency in 12-well plates and then deprived from serum for $24 \mathrm{~h}$. Thereafter, the cells were preincubated for $2 \mathrm{~h}$ with TKI $(10 \mu \mathrm{M})$ and then activated with either BSA $(30 \mathrm{mg} / \mathrm{ml})$ or TGF- $\beta 1(10 \mathrm{ng} / \mathrm{ml})$ for $24 \mathrm{~h}$. The relative mRNA expressions (fold induction) were quantified with real-time RT-PCR by normalizing to the expression of reference gene GAPDH. Data represent the mean \pm SEM for at least three different experiments. Differences versus control are presented as single dagger $p<0.05$, double dagger $p<0.01$ and triple dagger $p<0.001$. Differences versus other groups are single asterisk $p<0.05$, double asterisk $p<0.01$, triple asterisk $p<0.001$. 

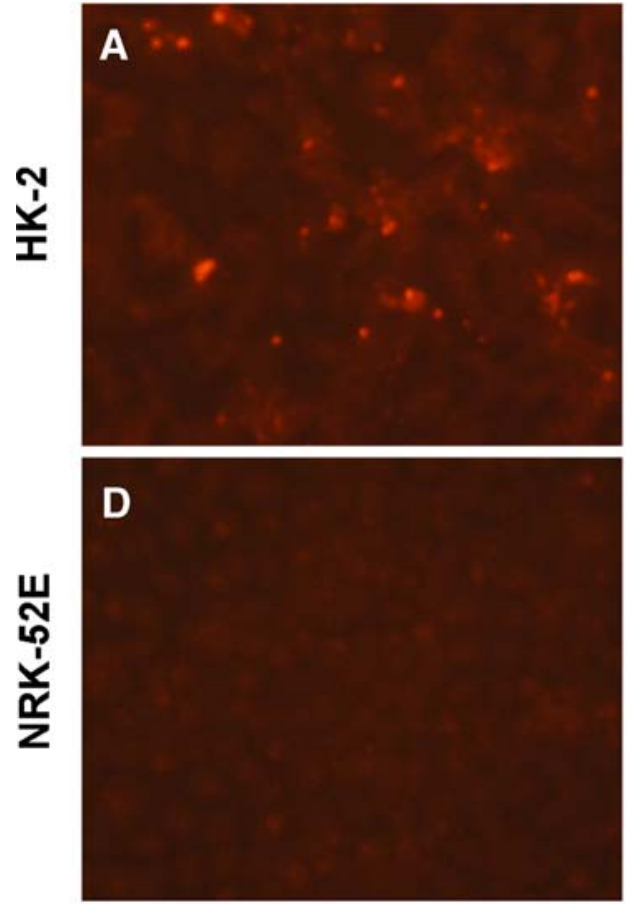

Rhodamine-LZM
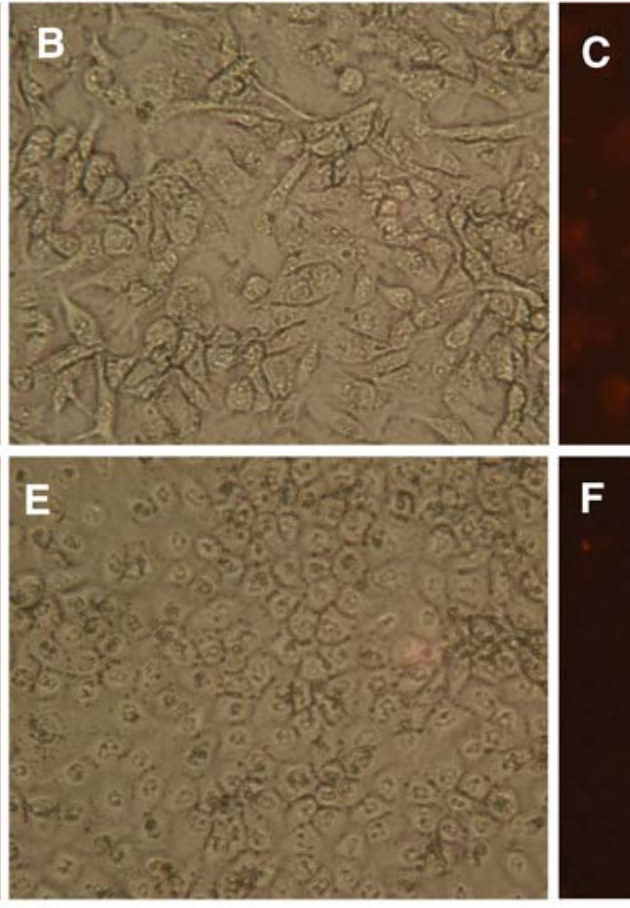
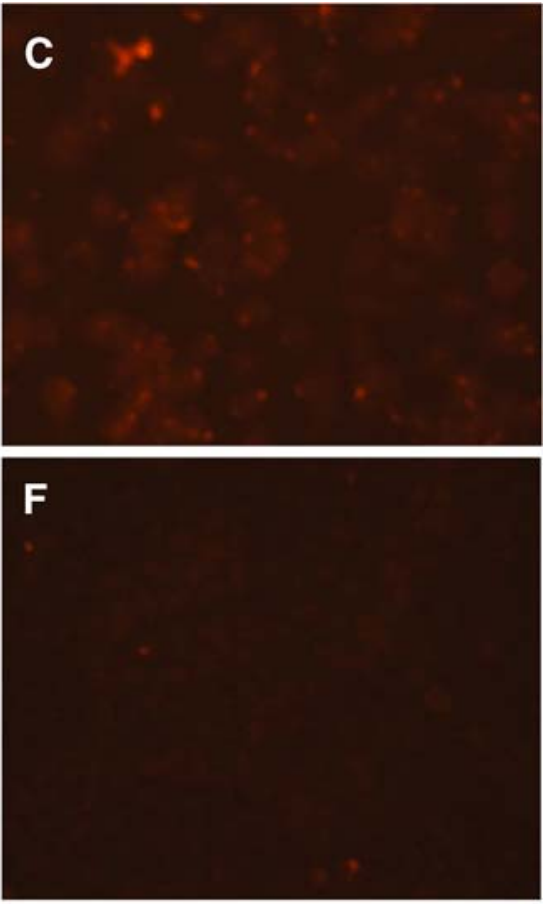

Rhodamine-LZM + LZM

Fig. 3. Fluorescent photomicrographs $\mathbf{A}, \mathbf{C}, \mathbf{D}, \mathbf{F}$ showing lysosomal uptake in HK-2 cells and NRK-52E cells after incubating with Rhodamine-ULS-lysozyme $(100 \mu \mathrm{g} / \mathrm{ml})$ at $37^{\circ} \mathrm{C}$ for $2 \mathrm{~h}$. For competition studies, lysozyme $(10 \mathrm{mg} / \mathrm{ml})$ was added $15 \mathrm{~min}$ before adding Rhodamine-ULS-lysozyme. Light photomicrographs $\mathbf{B}, \mathbf{E}$ demonstrate the confluency of the cells in culture plate.

\section{Statistical Analyses}

The statistical analyses were performed using Student's $t$ test with $p<0.05$ as the minimal level of significance. Results are presented as mean \pm SEM. Pharmacokinetic analysis of the serum TKI concentrations was performed using the Multifit program (Department of Pharmacokinetics and Drug Delivery, University of Groningen, The Netherlands).

\section{RESULTS}

\section{Synthesis and Characterization of TKI-ULS-LZM}

The synthesis scheme of TKI-LZM is shown in Fig. 1. In the first reaction step, TKI was efficiently coupled with ULS resulted in the TKI-ULS product. The analyses by HPLC, PtNMR and electronspray mass spectrometry (ESI-MS) confirmed a 1:1 coupling ratio of TKI and ULS. Subsequently, TKI-LZM conjugate was synthesized by reacting TKI-ULS at a 3:1 molar ratio with the renal carrier. The resulting TKILZM conjugate was characterized by ESI-MS of the intact conjugate and, after chemical destruction of the conjugate, by HPLC analysis of the coupled drug. The characterization of TKI-ULS, methionine-LZM and TKI-LZM are summarized in Table I. On average, the resulting conjugate contained one TKI molecule per molecule of carrier protein.

We found that the conjugate remained stable in PBS and serum since no drug was released after $24 \mathrm{~h}$ at $37^{\circ} \mathrm{C}$. In contrast, the drug was released slowly (4\% during $24 \mathrm{~h}$ ) upon incubation with $5 \mathrm{mM}$ glutathione, a likely intracellular ligand exchange molecule for the platinum ligand in ULS.

\section{Cell Experiments}

\section{Effect of TKI in NRK-52E Cells}

To investigate fibrotic events in renal tubular cells (NRK-52E), we treated the cells with natural activators such as a high concentration of albumin (BSA, $30 \mathrm{mg} / \mathrm{ml}$ ) or TGF$\beta 1(10 \mathrm{ng} / \mathrm{ml})$. Albumin stimulated the gene expression of the inflammation marker MCP-1 by 35 -fold, which in turn could be inhibited by $82 \%$ with TKI $(10 \mu \mathrm{M}$; Fig. 2A). Furthermore, albumin induced fibrosis markers such as TIMP-1 and $\alpha$-SMA significantly, while procollagen-I $\alpha 1$ was not elevated significantly (Fig. 2B-D). Treatment with TKI reduced the expression of these genes to levels even below basal expression, as was also observed in non-activated cells that were treated with the drug. This can be explained as we found that NRK-52E cells were activated after few days of culturing (unpublished data) and TKI inhibited this activation in both activated and non-activated cells. Similarly, TKI inhibited TGF- $\beta 1$-induced gene expressions of procollagen-I $\alpha 1$ and TIMP-1 significantly (Fig. 2B-D). MCP-1 expression was not elevated by TGF- $\beta 1$ treatment and accordingly, no effect of the drug could be seen.

\section{Renal Uptake Study of Rhodamine-ULS-LZM}

In contrast to untargeted drug, intracellular delivery of TKI after coupling to TKI-LZM is dependent on receptormediated endocytosis from the medium via the megalin receptor. We evaluated cellular uptake of RhodamineULS-LZM conjugates in NRK-52E and HK-2 cells by 


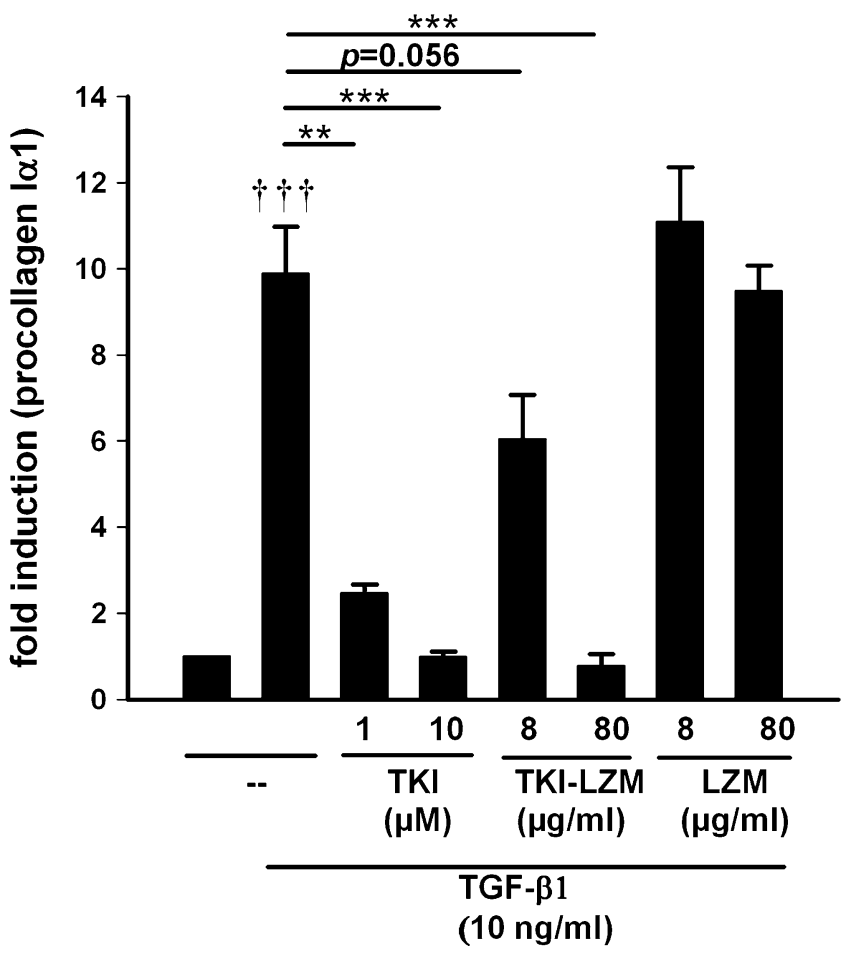

Fig. 4. Effects of TKI and TKI-lysozyme on procollagen- $1 \alpha 1$ gene expression in HK-2 cells. Cells were grown to $80 \%$ confluency and then deprived from serum for $24 \mathrm{~h}$. TKI-lysozyme ( 8 or $80 \mu \mathrm{g} / \mathrm{ml}$ are equivalent to 1 or $10 \mu \mathrm{M}$ TKI, respectively) or methionine-modified lysozyme (LZM, 8 or $80 \mu \mathrm{g} / \mathrm{ml}$ ) was added at the time of serum deprivation whereas TKI ( 1 or $10 \mu \mathrm{M})$ was added $1 \mathrm{~h}$ before adding TGF- $\beta 1$ to the cells. The relative mRNA expressions (fold induction) were quantified with real-time RT-PCR by normalizing to the expression of reference gene GAPDH. Data represent the mean \pm SEM for at least three experiments. Differences versus control is presented as triple dagger $p<0.001$. Differences versus other groups are double asterisk $p<0.01$ and triple asterisk $p<0.001$.

fluorescence microscopy. We found that proximal tubular cell of human origin ( $\mathrm{HK}-2$ cells) internalized the conjugate, while NRK-52E cells showed no uptake (Fig. 3). To further demonstrate that receptor-mediated uptake of the conjugate was involved, we competed for receptor binding and internalization with a high amount of non-modified LZM, which clearly reduced the uptake of the fluorescent protein.

\section{Effect of TKI and TKI-LZM in HK-2 Cells}

Next, we evaluated the inhibitory effect of TKI-LZM in HK-2 cells. After incubating the cells with TGF- $\beta 1$ for $24 \mathrm{~h}$, gene expression of procollagen-I $\alpha 1$ was tenfold increased which was reduced over $90 \%$ after treatment with TKI-LZM conjugate, comparable to the inhibition produced by an equimolar amount of free TKI $(10 \mu \mathrm{M})$. At lower concentrations, the conjugate inhibited procollagen-I $\alpha 1$ expression to a lesser extent whereas the equivalent amount of free drug still reduced it by $75 \%$ (Fig. 4). Treatment with the LZM carrier alone did not affect profibrotic signaling. From these results, we concluded that the conjugate was capable to deliver pharmacologically active drug to tubular cells in vitro.

\section{Animal Experiments}

Pharmacokinetics of the TKI-LZM Conjugate

We optimized the sampling protocol for the pharmacokinetic studies with TKI-LZM on the basis of our previous studies with drug-LZM conjugates (15) by choosing time points that allowed reliable estimation of the serum disappearance pharmacokinetic parameters as well as parameters reflecting renal residence. The serum-disappearance curve of TKI-LZM followed a two-compartment pharmacokinetic model (Fig. 5A). The pharmacokinetic data obtained from the serum-disappearance curve are given in Table II. Only carrier-bound TKI was detected in the serum, while free drug was absent. Furthermore, similar to other drug-LZM conjugates, TKI-LZM accumulated efficiently in the kidneys within $2 \mathrm{~h}$ ( $21 \%$ of injected dose or $18.1 \mu \mathrm{g} / \mathrm{g}$ TKI) following a single intravenous injection (Fig. 5B). The half life of degradation of the TKI-LZM conjugate was $37.7 \mathrm{~h}$ in kidneys which we calculated from the decline of renal TKI levels. Urine levels of TKI (Fig. 5C) indicated a prolonged and continuous excretion of the drug which corresponded to the continuous release profile in the kidneys.

The renal drug disappearance curve of the previous figure demonstrated that TKI-LZM conjugate resided in the kidneys for several days, releasing the drug slowly in the kidney tissue. Since we were interested in the fate of the drug-ULS part of the conjugates after their uptake by tubular cells, we injected Rhodamine-ULS-LZM as a model drug-LZM conjugate. We found that Rhodamine-ULS-LZM was accumulated in the tubular cells rapidly within $1 \mathrm{~h}$ after intravenous injection (Fig. 6A and D) which was well correlated with anti-LZM staining. While the carrier protein was hardly detectable at $t=$ $24 \mathrm{~h}$, Rhodamine was still detectable in a vesicular pattern (Fig. 6B and E). From these results, we concluded that the conjugate resided primarily in the lysosomal compartment after degradation of the protein backbone, from which it released the drug slowly into the surrounding environment. No staining for LZM and no fluorescence of rhodamine were found in untreated kidneys (Fig. 6C and F). In addition, only low levels of Rhodamine-ULS-LZM were detected in the liver, staining specifically in sinusoidal area (Fig. 6G) while no LZMpositive staining was observed in heart, spleen (Fig. $6 \mathrm{H}$ and I) and lungs (not shown).

\section{Effect of TKI and TKI-LZM in UUO Rats}

The efficacy of TKI-LZM was investigated in the shortterm UUO model which is known to cause renal inflammation and rapid activation of tubular cells and fibroblasts. Since the renally accumulated TKI-LZM provided prolonged and continuous local drug levels in our pharmacokinetic study, we administered only a single dose of the conjugate $2 \mathrm{~h}$ before the ureteral obstruction. On day 4, we found that the vehicletreated UUO rats had a high expression of vimentin, a marker for cell dedifferentiation, in renal tubular cells and $\alpha$ SMA, a marker for fibroblast activation, in tubulointerstitium compared to normal animals (Fig. 7, Table III). In addition, we found that a large number of infiltrated macrophages (ED1 positive cells) were present in the obstructed kidneys. This indicated that disease was significantly induced during the 
A

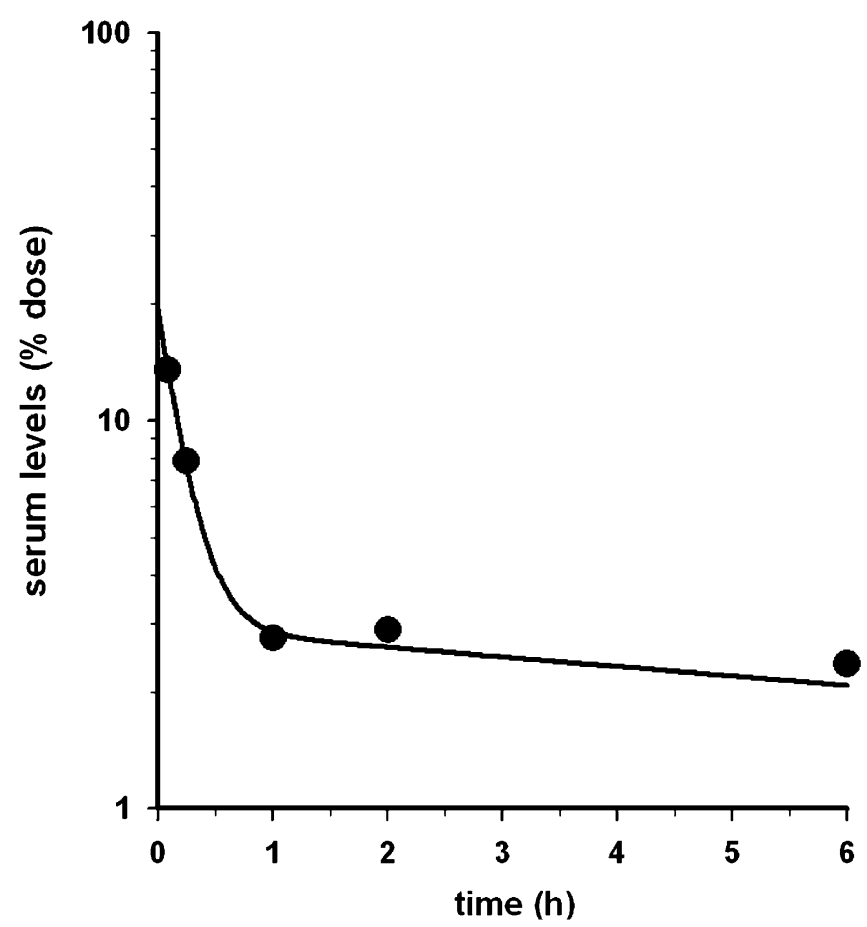

C

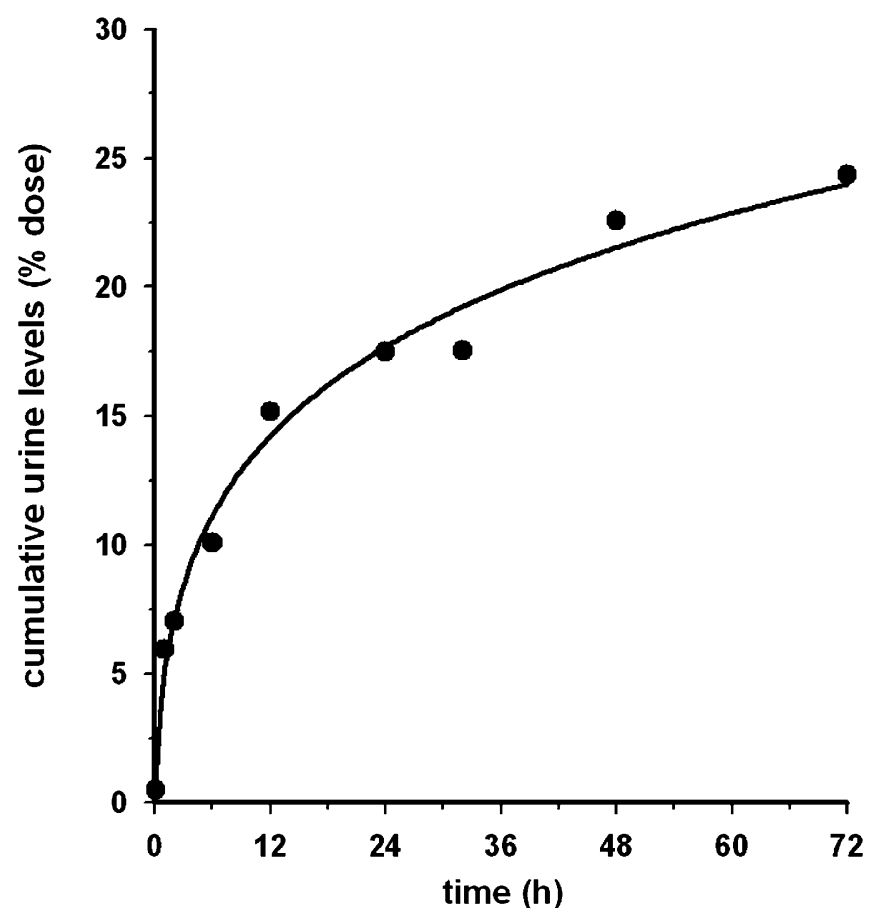

B

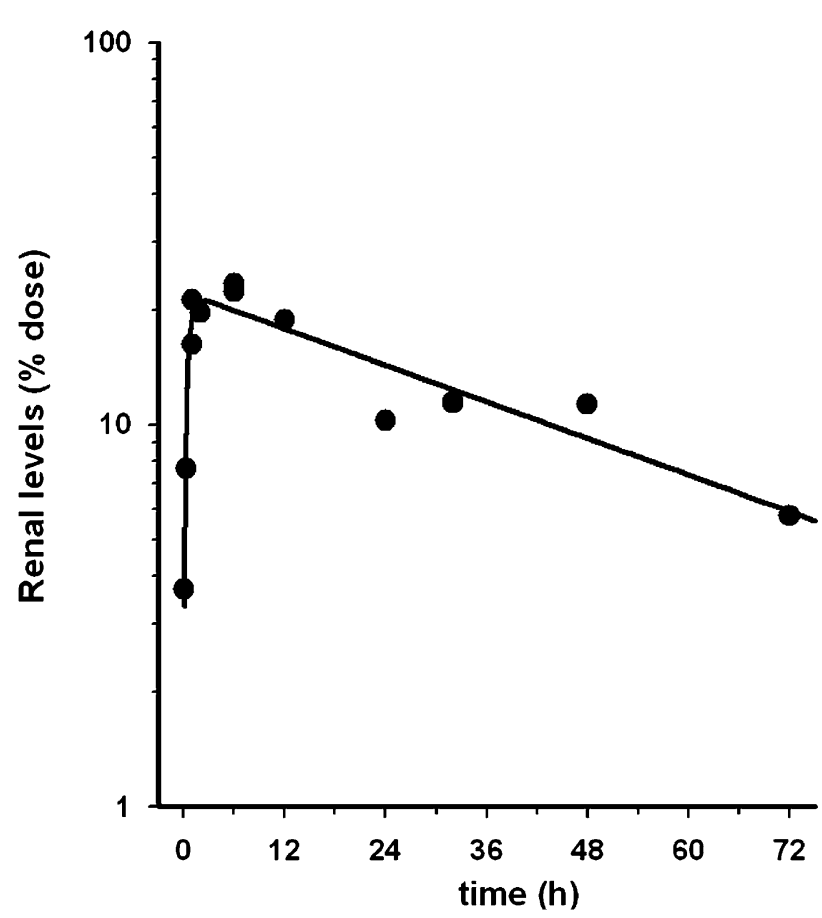

Fig. 5. Serum (A), renal (B) and urine (C) levels of TKI either bound or unbound to LZM. Each symbol represents TKI level as percent of injected dose in a single animal at each time point. The continuous line represents the pharmacokinetic data-fit curve (two-compartment model).

period of ligation. Treatment with a single dose of TKI-LZM substantially reduced vimentin and $\alpha$-SMA expression as well as retarded the macrophage influx in kidneys (Fig. 7, Table III). In addition, a single dose of free drug inhibited the tubular cells dedifferentiation at lesser extent but inhibited the expression of $\alpha$-SMA and ED-1 similar to TKI-LZM. This indicates that tubular cells-delivered kinase inhibitor exhibited a higher efficacy within the target organ.

As we found in our in vitro studies that TKI inhibited proinflammatory and profibrotic genes in renal tubular cells, 
Table II. Pharmacokinetic Parameters (Two-compartment Model) Derived from Serum Concentration-time Curves after a Single Intravenous Dose of $20 \mathrm{mg} / \mathrm{kg}$ of TKI-LZM in Rats

\begin{tabular}{clc}
\hline Parameters & Units & Values (Mean \pm SE) \\
\hline $\mathrm{V} 1$ & $\mathrm{ml}$ & $5.2 \pm 0.8$ \\
$\mathrm{CL}_{\text {ini }}$ & $\mathrm{ml} / \mathrm{h}$ & $21.6 \pm 2.8$ \\
$\mathrm{CL}$ & $\mathrm{ml} / \mathrm{h}$ & $1.04 \pm 0.76$ \\
$t_{1 / 2} \alpha$ & $\mathrm{h}$ & $0.14 \pm 0.03$ \\
$t_{1 / 2} \beta$ & $\mathrm{h}$ & $22.3 \pm 18.7$ \\
\hline
\end{tabular}

$V 1$ Volume of central compartment; $C L_{i n i}$ sum of elimination and distribution clearance from central compartment; $C L$ total serum clearance; $t_{1 / 2} \alpha$ distribution half life; $t_{1 / 2} \beta$ elimination half life

we analyzed the gene expression of MCP-1 and procollagen$1 \alpha 1$ in renal tissues. We found that the ligated kidney had significantly higher gene expression of both MCP-1 and procollagen- $1 \alpha 1$ compared to normal rats (Fig. 8). Moreover, treatment with TKI-LZM substantially reduced the MCP-1 gene expression but did not inhibit procollagen- $1 \alpha 1$ expression. Inhibition of macrophage influx with the conjugate may be due to the reduced MCP-1 expression since this chemoattractant plays an important role in the infiltration of immune cells. Furthermore, a single dose of free TKI did not lower the expression either MCP-1 or procollagen-1 1 1.

\section{DISCUSSION}

In the present study, we demonstrated the potential effects of the ALK5 inhibitor TKI in cultured renal tubular cells which stresses the importance of the inhibition of the TGF- $\beta$ pathway in these cells. In addition, we showed that cell-specific delivery of TKI in proximal tubular cells was achieved using the TKI-LZM conjugate which accumulated efficiently in kidney tubular cells and released TKI locally. We furthermore demonstrated that treatment with a single dose of TKI-LZM blocked inflammatory and fibrotic events
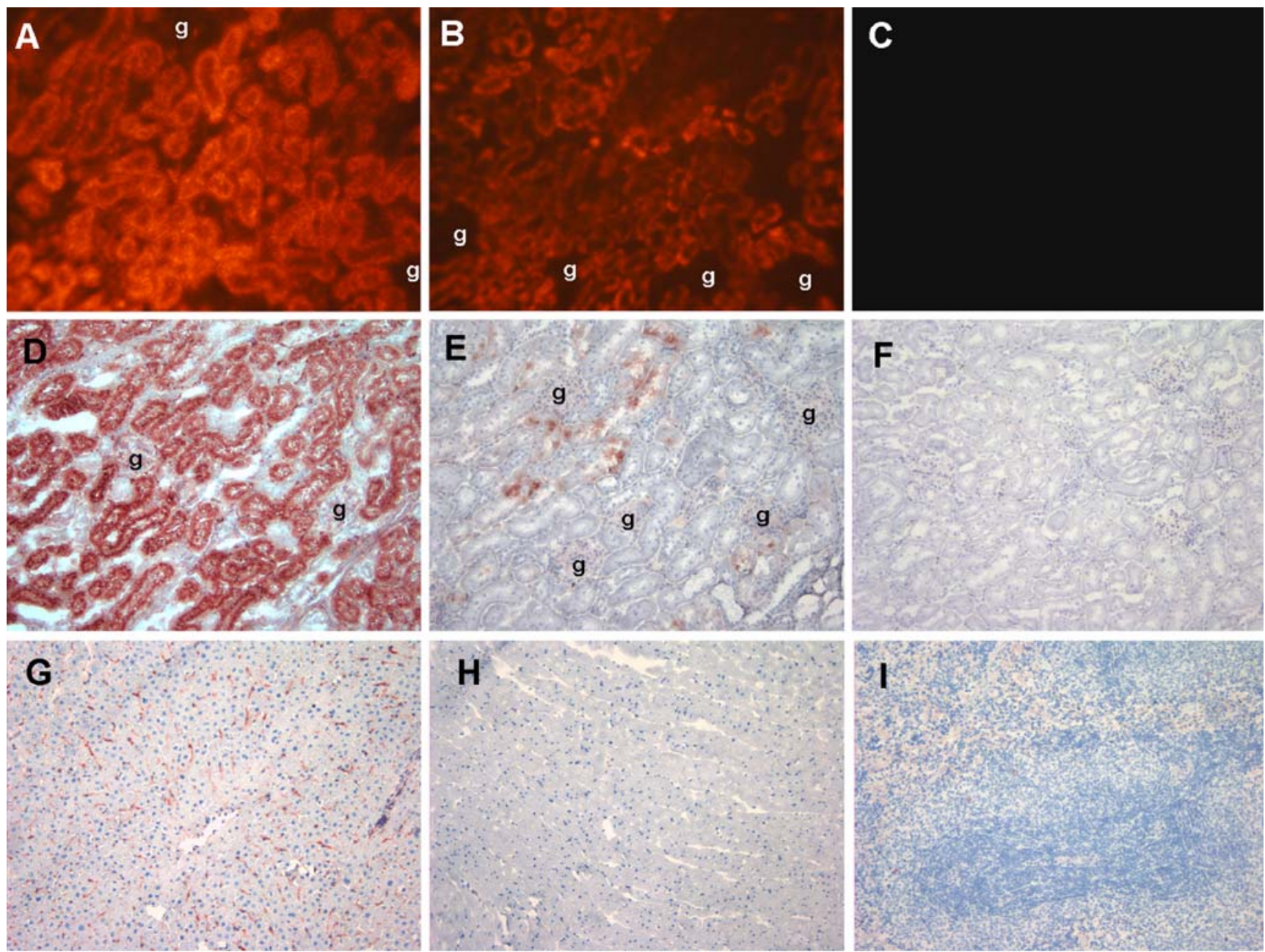

Fig. 6. Biodistribution of Rhodamine-ULS-lysozyme conjugate after a single intravenous administration to rats. Fluorescence photomicrographs A-C show the fluorescence in kidneys of Rhodamine-ULS-LZM treated rats at $t=1 \mathrm{~h}(\mathbf{A})$ and $t=24 \mathrm{~h}(\mathbf{B})$ and the autofluorescence in kidneys of untreated rats $(\mathbf{C})$. Tubular accumulation of the conjugate can be observed at both time points, while glomeruli (indicated with " $g$ ") are discernible as non-fluorescent areas in $\mathbf{A}$ and $\mathbf{B}$. Light photomicrograph D-F show anti-LZM immunostaining on kidneys of RhodamineULS-LZM treated rats at $t=1 \mathrm{~h}$ and $t=24 \mathrm{~h}$ while kidneys of untreated rats $(\mathbf{F})$ show negative staining. Note the pattern of the localization of anti-LZM staining and rhodamine auto-fluorescence in $\mathbf{A} v s \mathbf{D}$ and $\mathbf{B} v s \mathbf{E}$. Lysozyme was degraded after 24 h while rhodamine was still present in the tubules. G-I show anti-LZM staining at $1 \mathrm{~h}$ after rhodamine-ULS-LZM injection in liver, heart and spleen, respectively. Magnification $\times 100$ for all sections. 

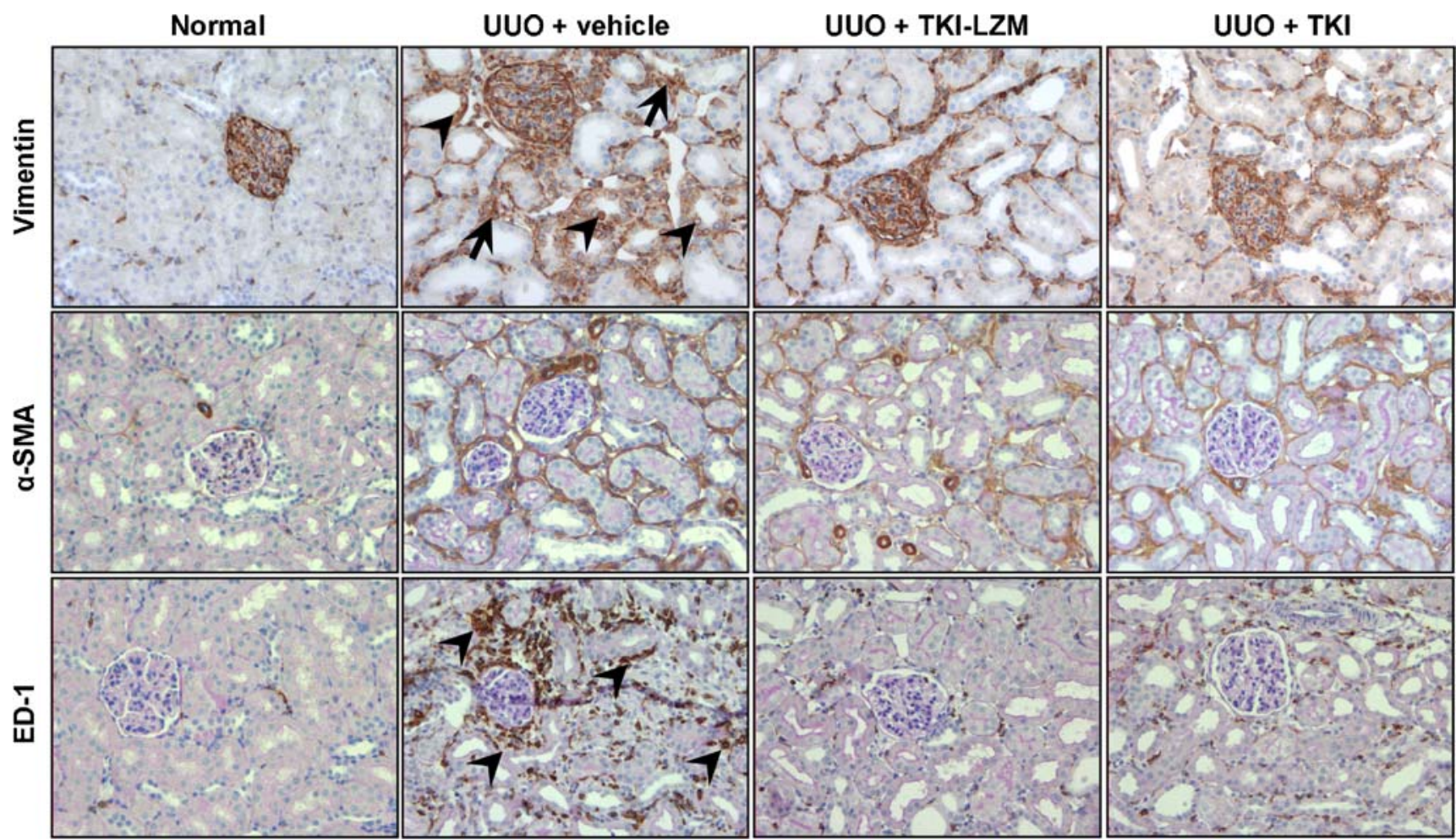

Fig. 7. Representative photomicrographs of the immunohistochemical staining for vimentin, alpha-smooth muscle actin ( $\alpha$-SMA) and ED-1 positive cells (infiltrated macrophages) in normal rats and the rats with unilateral ureteral obstruction (UUO). After ureteral obstruction, expression of vimentin in tubular cells (arrowheads) and in interstitium (arrows) was highly increased which was subsequently reduced by TKILZM. The expression of interstitial $\alpha$-SMA and macrophages (arrowheads) was enhanced after renal ligation and then reduced with either TKI-LZM or TKI. Magnification $\times 200$.

in the obstructive nephropathy. Our results suggest that inhibition of TGF- $\beta$ pathway in renal tubular cells using our cell-specific drug delivery approach can be an interesting strategy to treat renal diseases.

Activation of tubular cells is a crucial event during renal injury which leads to tubular cell dedifferentiation and induction of inflammation and fibrogenesis. Tubular cell activation can be caused by many factors such as filtered proteins, cytokines and oxidative stress which initiate multiple events in the cells. In the present study, TKI inhibited proinflammatory and profibrotic factors induced by either albumin or TGF- $\beta 1$ in cultured rat kidney tubular cells. The inhibited genes are highly relevant since they are stimulated during renal fibrosis as demonstrated in multiple studies $(10,16,17)$. In addition, we compared the effectivity of TKI with the p38 MAPK inhibitor SB202190, which was used for the development of another drug-LZM conjugate (15). We found that TKI was more potent than SB202190 in inhibiting TGF- $\beta 1$-induced genes. For instance, TKI inhibited procolla- gen-1 1 1 expression by $100 \%$ compared to SB202190 which only inhibited by $50 \%$ at $10 \mu \mathrm{M}$ concentration in HK-2 cells. These data suggest that TKI is highly capable to inhibit the activation of tubular cells caused by natural activators.

To deliver TKI selectively to proximal tubular cells, we conjugated TKI to LZM. LZM is a low molecular weight protein which filters freely through glomerulus and rapidly internalized via megalin receptors in proximal tubular cells in kidney (18). Coupling of TKI to LZM via the coordinative linker ULS provided a stable and biologically active conjugate. Our in vitro data and the in vivo pharmacokinetic study demonstrated that TKI-LZM remained stable in serum and accumulated efficiently and specifically into the targeted tubular cells in the kidney. Within the tubular cells, TKI was released possibly by an intracellular ligand such as glutathione which has been shown to trigger the release of ligand from platinum (19). This was confirmed in the present study. Since the ligand-exchange behavior of platinum-coordinated compounds is quite slow (20), drug-ULS-LZM conjugates have

Table III. Scores for the Immunohistochemical Stainings of Vimentin-Positive Tubular Cells, Ed-1 Positive Cells (macrophages) and Interstitial Alpha-Smooth Muscle Actin ( $\alpha$-SMA) in the Renal Cortex of the Normal Rats and UUO Rats with Different Treatments

\begin{tabular}{lcccc}
\hline \multicolumn{1}{c}{ Immunostainings } & Normal & UUO + vehicle & UUO + TKI-LZM & UUO + TKI \\
\hline Vimentin-expressing tubular cells & - & ++++ & ++ & +++ \\
Interstitial $\alpha$-SMA (activated fibroblasts) & $+/-$ & +++ & ++ & ++ \\
ED-1 positive cells (monocytes/macrophages) & $+/-$ & ++++ & ++ & ++ \\
\hline
\end{tabular}

Stainings were scored as follows: -, no staining; +/-, very weak; +, weak; ++, moderate;+++, strong; ++++, very strong staining. 


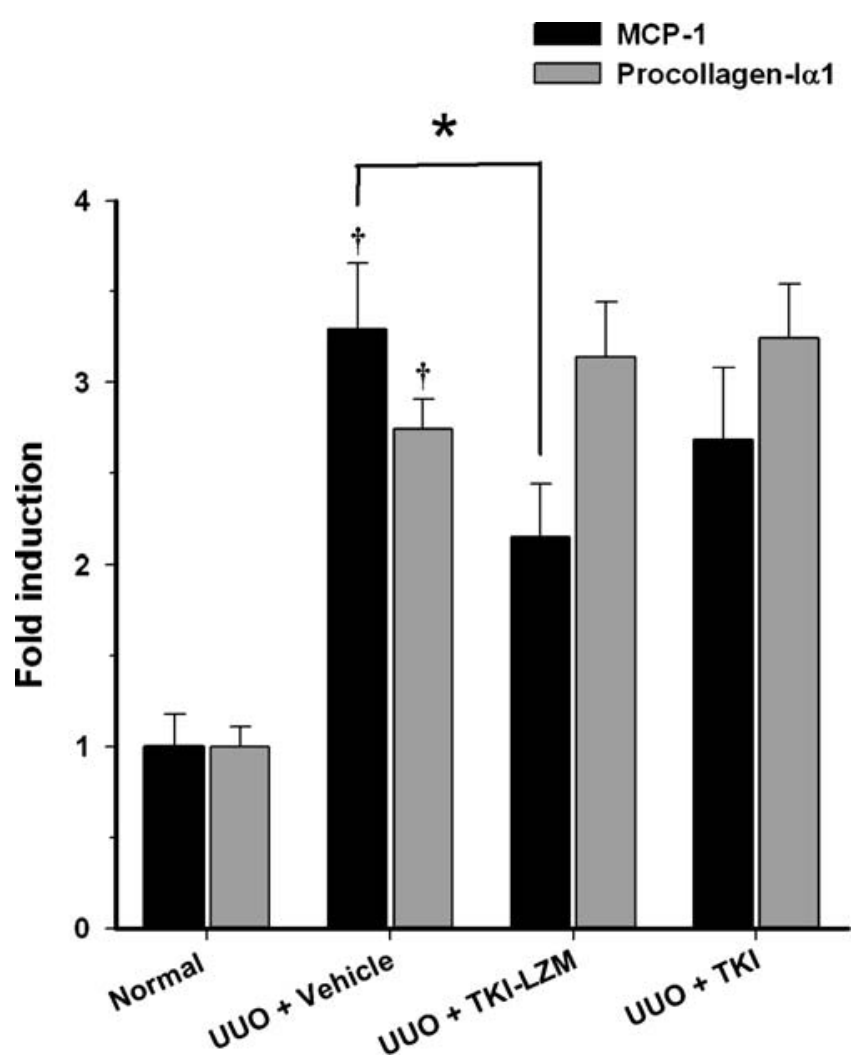

Fig. 8. Gene expression levels of MCP-1 and procollagen- $1 \alpha 1$ in renal cortex of normal rats and vehicle-treated, TKI-LZM-treated and TKI-treated rats after unilateral ureteral obstruction (UUO). Each bar represents the mean \pm SEM for $n=5$, except for normal rats $(n=4)$. The relative mRNA expressions (fold induction) were quantified with real-time RT-PCR by normalizing to the expression of reference gene GAPDH. Difference between normal rats and vehicle-treated UUO rats are presented as dagger $p<0.01$. Differences versus other groups are asterisk $p<0.05$.

an adequate stability which provides their intact accumulation in renal tubular cells. As indicated by the renal disappearance and urinary excretion curves, the prolonged depot of the TKI-LZM conjugate in the kidney can therefore be explained by the slow intracellular release of TKI from the conjugate. Furthermore, in vivo data of rhodamine-ULS-LZM conjugate confirmed that even after degradation of LZM, drug-ULS stays inside the targeted tubular cells and releases drug locally.

Cisplatin and related cytostatic compounds are known to cause nephrotoxicity (21), and the use of cisplatinum as a linker in drug-LZM conjugates may infer unwanted toxicity to the renal proximal tubule. In our earlier studies we have investigated the platinum-related nephrotoxicity of ULS in rat renal tubular cells in vitro with cell viability assays and in vivo in rats. Both types of experiments, in which toxicity was evaluated by apoptosis assays and renal function tests, did not show any nephrotoxicity (15). This observation is corroborated by the present results obtained with TKI-LZM. If toxic effects of the ULS linker would have been prevalent, this would have worsened the viability of tubular cells, thereby aggravating the toxic effect of ureter obstruction. In contrast, the beneficial effects of the delivered drug prevailed and disease-related markers were inhibited. This demonstrated that ULS can be used safely as a linker for renal drug delivery.
In our uptake study in vitro, we found that HK-2 tubular cells were capable of internalizing proteins whereas NRK52E did not show any cellular uptake. Therefore, we tested the activity of the TKI-LZM conjugate in HK-2 cells. Interestingly, TKI-LZM inhibited the TGF- $\beta 1$-induced expression of procollagen- $1 \alpha 1$. Such an effect can only take place after internalization and processing of the conjugate into active drug by these cells.

Unilateral ureteral obstruction (UUO) is a well known animal model to develop renal fibrosis and this particular model is associated with abundant expression of TGF- $\beta$ and its receptors, leading to the activation of tubular cells and fibroblasts $(22,23)$. Since the short-term UUO model progresses rapidly to a mild-stage of fibrogenesis, it seemed a suitable model to examine the efficacy of TKI-LZM conjugate. However, ureteral ligation will prevent renal filtration of low molecular weight proteins, thereby also preventing TKILZM to accumulate in the ligated kidney. We therefore decided to evaluate the efficacy of a single dose of the conjugate which was allowed to accumulate in the kidneys before the obstructive procedure. We hypothesized from our pharmacokinetic study that the continuous release of TKI from the locally deposited TKI-LZM would effectuate its inhibitory effects during the following days. We observed 
ameliorative effects of the single dose of TKI-LZM on various crucial early events of the obstructive nephropathy such as tubular cell dedifferentiation, macrophage infiltration and the activation of fibroblasts. Unexpectedly, free drug also inhibited macrophage influx and fibroblast activation. Since TKI is a highly potent drug as shown in our in vitro studies, the latter effects might be due to its systemic action, and thus may relate to a prophylactic activity of the free drug. Our data with untargeted TKI demonstrate the strong potency of the drug, which appears to have an effect even at low doses. More importantly, effects on the tubular cell dedifferentiation were more prominent with TKI-LZM than with untargeted TKI which illustrates its local effect within the target cells. Furthermore, the inhibition of MCP-1 gene expression was found only with the conjugate which also demonstrates the improved efficacy of the conjugate. MCP-1 blockade is highly important process to retard the progression of the renal disease since MCP-1 expression increases continuously in time following ureteral obstruction (24). In earlier studies, inhibition of MCP-1 using gene therapy or MCP-1 antagonists has been proven to be beneficial for the treatment of renal fibrosis in UUO $(25,26)$. In contrast to the free drug, it is unlikely that the TKI-LZM conjugate acted in a prophylactic manner, although it also was administered before induction of disease. First of all, at $2 \mathrm{~h}$ post-injection, most of the conjugate will reside in the lysosomal compartment of the tubular cells, while the delivered drug supposedly should act in the cytosol of the cells. During the following 3-4 days, TKILZM will slowly release its coupled drug. In contrast to TKILZM, the administered free TKI is administered in its pharmacological active state, and it is more likely that the observed activity of this drug is due to a prophylactic effect rather than a therapeutic effect. Possibly, the observed effect of free TKI relates to anti-inflammatory activity in immune cells at the onset of the UUO-induced nephropathy. Elimination of the free drug during the first day will prevent its presence in the kidney during later stages of the disease progression, i.e. at days $2-4$.

In conclusion, the present study reveals that targeting of a TGF- $\beta$ kinase inhibitor to tubular cells is in potential a promising approach for the treatment of renal diseases. Cellspecific delivery of such compounds can successfully be accomplished using our approach that affords a sustained release of the active drug for several days within the target cells. This local release yields substantial effects in the UUO model.

\section{ACKNOWLEDGEMENTS}

J. Visser, C. Reker-Smit, P.A. Klok, M. Bulthuis and M. van Dalen are acknowledged for their excellent technical assistance. Authors are also thankful to A. van Dam and M. Jeronimus-Stratingh for their assistance in mass spectrometry analysis, and acknowledge colleagues at Kreatech for critical reading of the manuscript.

Open Access This article is distributed under the terms of the Creative Commons Attribution Noncommercial License which permits any noncommercial use, distribution and reproduction in any medium, provided the original author(s) and source are credited.

\section{REFERENCES}

1. E. P. Bottinger, and M. Bitzer. TGF-beta signaling in renal disease. J. Am. Soc. Nephrol 13:2600-2610 (2002).

2. M. Zeisberg, and R. Kalluri. The role of epithelial-to-mesenchymal transition in renal fibrosis. J. Mol. Med 82:175-181 (2004).

3. A. A. Eddy. Molecular insights into renal interstitial fibrosis. $J$. Am. Soc. Nephrol 7:2495-2508 (1996).

4. H. W. Schnaper, T. Hayashida, and A. C. Poncelet. It's a Smad world: regulation of TGF-beta signaling in the kidney. J. Am. Soc. Nephrol 13:1126-1128 (2002).

5. N. J. Laping. ALK5 inhibition in renal disease. Curr. Opin. Pharmacol 3:204-208 (2003).

6. J. S. Sawyer, D. W. Beight, K. S. Britt, B. D. Anderson, R. M. Campbell, T. Goodson Jr., D. K. Herron, H. Y. Li, W. T. McMillen, N. Mort, S. Parsons, E. C. Smith, J. R. Wagner, L. Yan, F. Zhang, and J. M. Yingling. Synthesis and activity of new aryl- and heteroaryl-substituted 5,6-dihydro-4H-pyrrolo[1,2-b]pyrazole inhibitors of the transforming growth factor-beta type I receptor kinase domain. Bioorg. Med. Chem. Lett 14:3581-3584 (2004).

7. J. Singh, C. E. Chuaqui, P. A. Boriack-Sjodin, W. C. Lee, T. Pontz, M. J. Corbley, H. K. Cheung, R. M. Arduini, J. N. Mead, M. N. Newman, J. L. Papadatos, S. Bowes, S. Josiah, and L. E. Ling. Successful shape-based virtual screening: the discovery of a potent inhibitor of the type I TGFbeta receptor kinase (TbetaRI). Bioorg. Med. Chem. Lett 13:4355-4359 (2003).

8. P. Bonniaud, P. J. Margetts, M. Kolb, J. A. Schroeder, A. M. Kapoun, D. Damm, A. Murphy, S. Chakravarty, S. Dugar, L. Higgins, A. A. Protter, and J. Gauldie. Progressive transforming growth factor \{beta\}1-induced lung fibrosis is blocked by an orally active ALK5 kinase inhibitor. Am. J. Respir. Crit. Care Med 171:889-898 (2005).

9. A. C. de Gouville, V. Boullay, G. Krysa, J. Pilot, J. M. Brusq, F. Loriolle, J. M. Gauthier, S. A. Papworth, A. Laroze, F. Gellibert, and S. Huet. Inhibition of TGF-beta signaling by an ALK5 inhibitor protects rats from dimethylnitrosamine-induced liver fibrosis. Br. J. Pharmacol 145:166-177 (2005).

10. E. T. Grygielko, W. M. Martin, C. Tweed, P. Thornton, J. Harling, D. P. Brooks, and N. J. Laping. Inhibition of gene markers of fibrosis with a novel inhibitor of transforming growth factor-beta type I receptor kinase in puromycin-induced nephritis. J. Pharmacol. Exp. Ther 313:943-951 (2005).

11. J. A. Moon, H. T. Kim, I. S. Cho, Y. Y. Sheen, and D. K. Kim. IN-1130, a novel transforming growth factor-beta type I receptor kinase (ALK5) inhibitor, suppresses renal fibrosis in obstructive nephropathy. Kidney Int 70:1234-1243 (2006).

12. M. O. Li, Y. Y. Wan, S. Sanjabi, A. K. Robertson, and R. A. Flavell. Transforming growth factor-beta regulation of immune responses. Annu. Rev. Immunol 24:99-146 (2006).

13. E. J. F. Franssen, F. Moolenaar, D. De Zeeuw, and D. K. F. Meijer. Drug targeting to the kidney with low-molecular-weight proteins. Adv. Drug Deliv. Rev 14:67-88 (1994).

14. M. Haas, F. Moolenaar, D. K. Meijer, and D. De Zeeuw. Specific drug delivery to the kidney. Cardiovasc. Drugs Ther 16:489-496 (2002).

15. J. Prakash, M. Sandovici, V. Saluja, M. Lacombe, R. Q. Schaapveld, B. M. de, G. H. van, R. H. Henning, J. H. Proost, F. Moolenaar, G. Keri, D. K. Meijer, K. Poelstra, and R. J. Kok. Intracellular delivery of the P38 MAPK inhibitor SB202190 in renal tubular cells: a novel strategy to treat renal fibrosis. $J$. Pharmacol. Exp. Ther 319:8-19 (2006).

16. C. Duymelinck, S. E. Dauwe, K. E. De Greef, D. K. Ysebaert, G. A. Verpooten, and M. E. De Broe. TIMP-1 gene expression and PAI-1 antigen after unilateral ureteral obstruction in the adult male rat. Kidney Int 58:1186-1201 (2000).

17. C. M. Lloyd, A. W. Minto, M. E. Dorf, A. Proudfoot, T. N. Wells, D. J. Salant, and J. C. Gutierrez-Ramos. RANTES and monocyte chemoattractant protein-1 (MCP-1) play an important role in the inflammatory phase of crescentic nephritis, but only MCP-1 is involved in crescent formation and interstitial fibrosis. J. Exp. Med 185:1371-1380 (1997).

18. M. Haas, F. Moolenaar, D. K. Meijer, and D. De Zeeuw. Specific drug delivery to the kidney. Cardiovasc. Drugs Ther 16:489-496 (2002).

19. K. Ikeda, K. Miura, S. Himeno, N. Imura, and A. Naganuma. Glutathione content is correlated with the sensitivity of lines of 
PC12 cells to cisplatin without a corresponding change in the accumulation of platinum. Mol. Cell Biochem 219:51-56 (2001).

20. J. Reedijk. New clues for platinum antitumor chemistry: kinetically controlled metal binding to DNA. Proc. Natl. Acad. Sci. U. S. A 100:3611-3616 (2003).

21. T. Taguchi, A. Nazneen, M. R. Abid, and M. S. Razzaque. Cisplatin-associated nephrotoxicity and pathological events. Contrib. Nephrol 148:107-121 (2005).

22. P. M. Sutaria, M. Ohebshalom, T. A. McCaffrey, E. D. Vaughan Jr., and D. Felsen. Transforming growth factor-beta receptor types I and II are expressed in renal tubules and are increased after chronic unilateral ureteral obstruction. Life Sci 62:1965-1972 (1998).

23. K. Fukuda, K. Yoshitomi, T. Yanagida, M. Tokumoto, and H. Hirakata. Quantification of TGF-beta1 mRNA along rat nephron in obstructive nephropathy. Am. J. Physiol. Renal. Physiol 281:F513-F521 (2001).
24. V. Vielhauer, H. J. Anders, M. Mack, J. Cihak, F. Strutz, M Stangassinger, B. Luckow, H. J. Grone, and D. Schlondorff. Obstructive nephropathy in the mouse: progressive fibrosis correlates with tubulointerstitial chemokine expression and accumulation of $\mathrm{CC}$ chemokine receptor 2- and 5-positive leukocytes. J. Am. Soc. Nephrol 12:1173-1187 (2001).

25. K. Kitagawa, T. Wada, K. Furuichi, H. Hashimoto, Y. Ishiwata, M. Asano, M. Takeya, W. A. Kuziel, K. Matsushima, N. Mukaida, and H. Yokoyama. Blockade of CCR2 ameliorates progressive fibrosis in kidney. Am. J. Pathol 165:237-246 (2004).

26. T. Wada, K. Furuichi, N. Sakai, Y. Iwata, K. Kitagawa, Y. Ishida, T. Kondo, H. Hashimoto, Y. Ishiwata, N. Mukaida, N. Tomosugi, K. Matsushima, K. Egashira, and H. Yokoyama. Gene therapy via blockade of monocyte chemoattractant protein-1 for renal fibrosis. J. Am. Soc. Nephrol 15:940-948 (2004). 